\title{
Pulmonary manifestations of inflammatory bowel disease
}

\author{
Jacob Gelberg MD FRCPC FCCP ${ }^{1}$, David Ryan Stather MD FRCPC FCCP²
}

T

hree patients with Crohn disease were evaluated for cough and dyspnea. A 63-year-old woman was found to have bronchiolitis obliterans and bronchiectasis that responded to oral prednisone (Figure 1A). A 38-year-old man was found to have airflow obstruction and pulmonary nodules. Open lung biopsy revealed necrobiotic nodules and bronchiolitis obliterans (Figure 1B). A 49-year-old man experienced severe airflow obstruction and was confirmed via bronchoscopy and imaging to have three different manifestations of inflammatory bowel disease (IBD); tracheobronchitis, bronchiectasis and bronchiolitis obliterans (Figures 1C and 1D). Improvements in airflow obstruction and symptoms occurred with oral prednisone.

Although pulmonary manifestations have historically been believed to be a rare complication of IBD, recent publications suggest that this may be more frequent than previously recognized $(1,2)$. Respiratory manifestations of IBD are varied and include bronchiectasis (most common), tracheobronchitis (including rare laryngeal and glottic involvement), chronic bronchitis, bronchiolitis obliterans, pulmonary nodules (necrobiotic or granulomatous), pleuritis and a variety of parenchymal and interstitial diseases (1). IBD patients are at increased risk for venous thromboembolic disease and a growing body of literature suggests a link between IBD and sarcoidosis, asthma and alpha-1 antitrypsin deficiency (1). Pulmonary manifestations rarely precede the diagnosis of IBD, do not correlate with colonic disease and may present years after colonic disease is controlled (3). A high index of suspicion for respiratory disorders is warranted in patients with IBD because it may be easily identified with appropriate history, pulmonary function testing and imaging, and may be treatable if identified early.

\section{KEY LEARNING POINTS}

- A high index of suspicion for respiratory disorders is warranted in patients with IBD.

- Pulmonary manifestations rarely precede the diagnosis of IBD and may present years after colonic disease is controlled.

- Early identification of respiratory manifestations of IBD is important as early therapy may improve long-term outcomes in these patients.

DISCLOSURES: This work was performed at the Division of Respiratory Medicine, University of Calgary, Calgary, Alberta. The authors have no financial disclosures or conflicts of interest to declare.

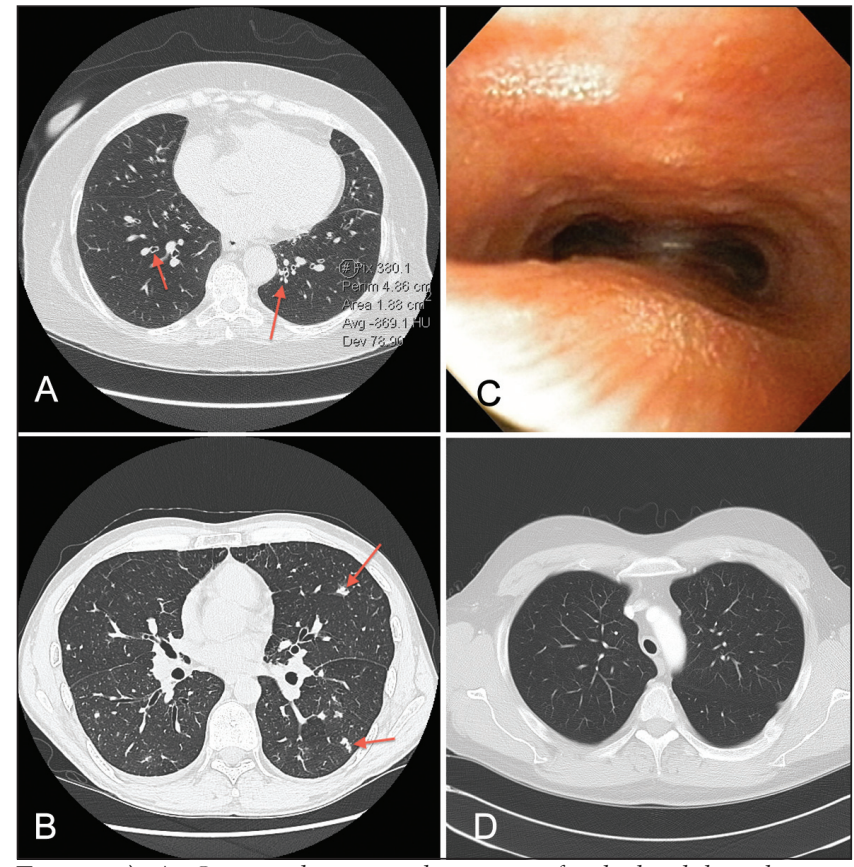

Figure 1) A Computed tomography image of cylindrical bronchiectasis (arrows) and biopsy-proven bronchiolitis obliterans in a 63-year-old woman with Crohn disease who responded to oral prednisone. B Computed tomography image of open lung biopsy-proven necrobiotic lung nodules (arrows) in a 38-year-old man with Crohn disease. C Bronchoscopic image of the abnormal trachea and main carina in inflammatory bowel disease-related tracheobronchitis in a patient with Crohn disease. Note the concentric tracheal and mainstem bronchi narrowing, loss of the normal visibility of the cartilaginous rings and mucosal studding. D Computed tomography image of the concentric tracheal narrowing in inflammatory bowel disease-related tracheobronchitis in a 49-year-old man with Crohn disease (tracheal lumen $1.1 \mathrm{~cm} \times 0.7 \mathrm{~cm}$ )

\section{REFERENCES}

1. Black H, Mendoza M, Murin S. Thoracic manifestations of inflammatory bowel disease. Chest 2007;131:524-32.

2. Camus P, Colby TV. The lung in inflammatory bowel disease. Eur Respir J 2000;15:5-10.

3. Kuzniar T, Sleiman C, et al. Severe tracheobronchial stenosis in a patient with Crohn's disease. Eur Respir J 2000;15:209-12.

The 'Images in Respiratory Medicine' section of the Canadian Respiratory Journal aims to highlight the importance of visual interpretation, whether physiological, radiological, bronchoscopic, surgical/thorascopic or histological, in the diagnosis of chest diseases. Submissions should exemplify a classic, particularly dramatic or intriguing presentation of a disease while offering an important educational message to the reader (insightful diagnostic pearls or differential diagnosis, etc). This section is not intended to be a vehicle for publication of case reports (see the Clinical-Pathologic Conferences for case-based leaning series).

${ }^{1}$ Department of Medicine, McMaster University, Hamilton, Ontario; ${ }^{2}$ Department of Medicine, University of Calgary, Calgary, Alberta Correspondence: Dr David Ryan Stather, Division of Respiratory Medicine, Health Sciences Center, 3330 Hospital Drive Northwest, Calgary, Alberta T2N 4N1. Telephone 403-210-3866, fax 403-944-1577, e-mail davestather@yahoo.ca 


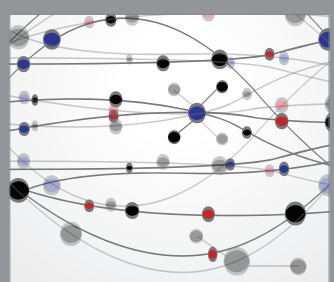

The Scientific World Journal
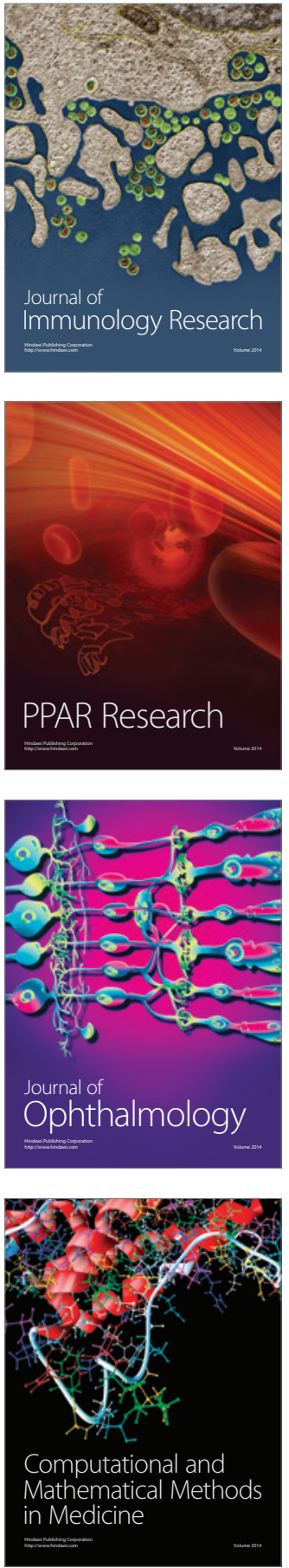

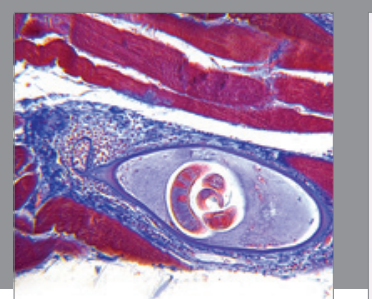

Gastroenterology Research and Practice

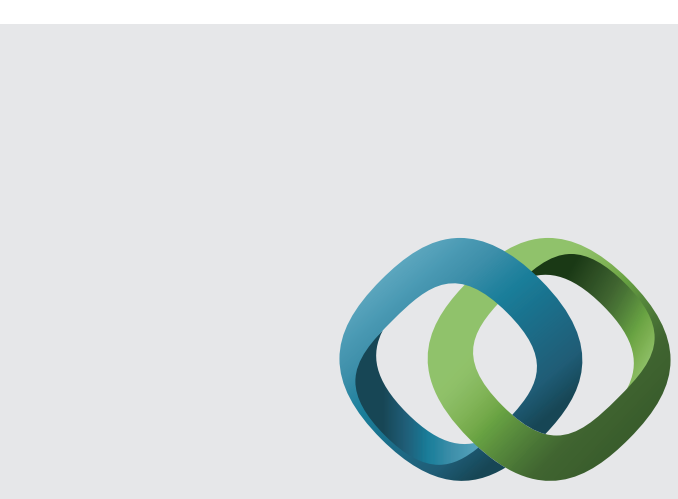

\section{Hindawi}

Submit your manuscripts at

http://www.hindawi.com
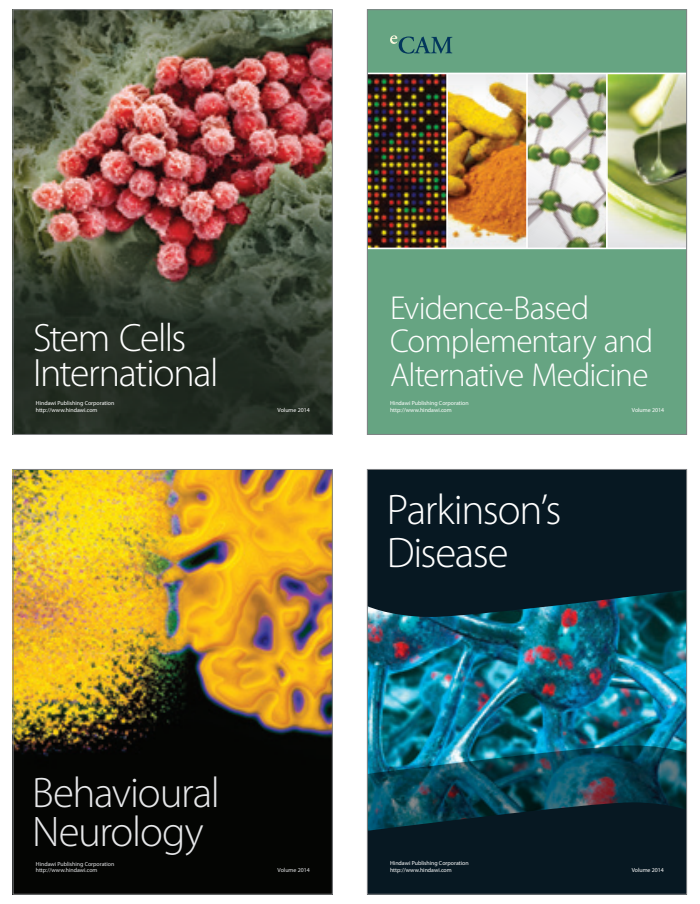
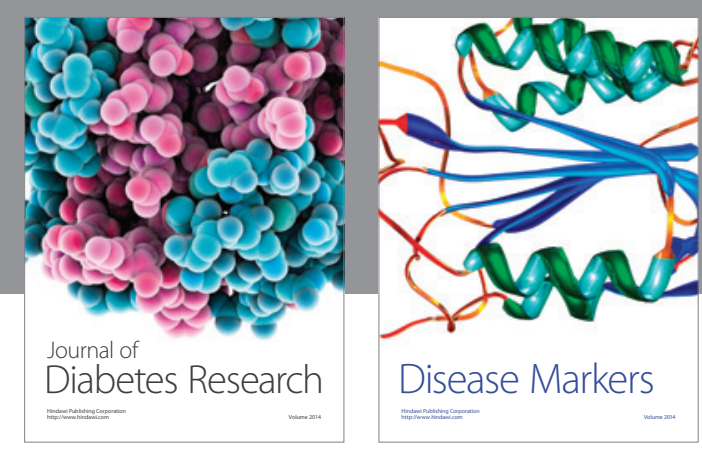

Disease Markers
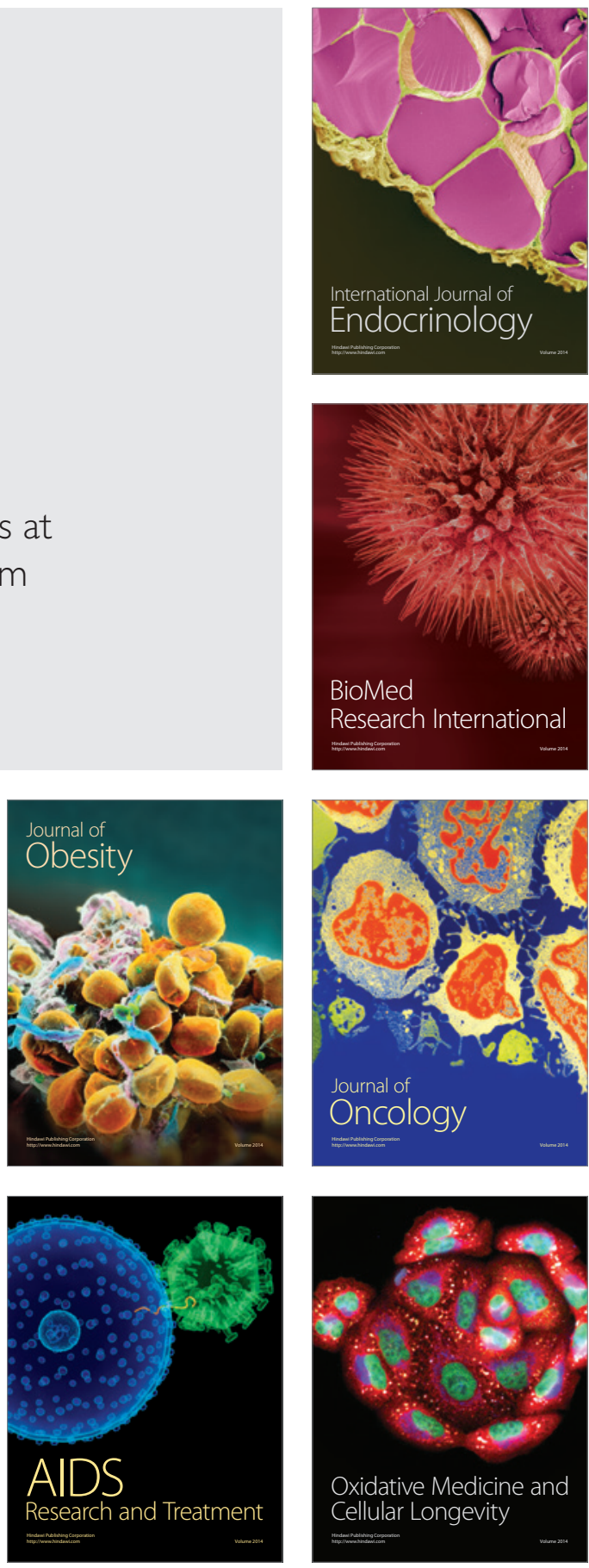